\title{
SISTEM PEMERIKSAAN KAPAL BERBASIS DESKTOP PADA BIDANG KESELAMATAN BERLAYAR KANTOR KESYAHBANDARAN UTAMA
}

\author{
Nurul Fadillah Novistia ${ }^{1)}$, Kamaruddin Tone $^{2)}$, Faisal Rahman ${ }^{3)}$ \\ 1,2,3 Jurusan Sistem Informasi, Fakultas Sains dan Teknologi, UIN Alauddin \\ ${ }^{1,2,3}$ Samata Kab. Gowa (Kampus 2) \\ E-mail: nurul.fadillah.novi@gmail.com ${ }^{1)}$,kamaruddin.tone@uin-alauddin.ac.id ${ }^{2)}$,Faisal.rahman@uin-alauddin.ac.id ${ }^{3)}$
}

\begin{abstract}
Abstrak - Kantor Kesyahbandaran Kelas Utama Makassar merupakan unit kerja organisasi kepelabuhanan yang bernaung di bawah Kementerian Perhubungan Republik Indonesia. Dalam bidang keselamatan berlayar bertanggung jawab atas lalu lintas kapal yang keluar masuk dan apa yang dibawanya. Oleh karena itu, bidang keselamatan berlayar harus mempunyai sistem dan cara kerja yang ekstra teliti demi keselamatan dan keamanan apa yang dibawanya baik penumpang ataupun barang. Sebagai salah satu kantor besar di pemerintahan, kantor Kesyahbandaran Utama Makassar Bidang Keselamatan Berlayar membutuhkan teknologi-teknologi yang mampu menunjang perkembangan kinerja dan keselamatan kapal. Penelitian ini menggunakan metode penelitian kualitatif sedang metode pengumpulan data yang digunakan yakni observasi dan wawancara. Adapun metode perancangannya menggunakan Data Flow Diagram (DFD). Aplikasi ini menyimpulkan bahwa fungsi yang diharapkan semuanya berhasil sesuai dengan keinginan. Kesimpulannya bahwa aplikasi ini dapat membantu pegawai kantor dalam penginputan data kapal, pemeriksaan dokumen dan informasi dokumen yang layak, dan penerbitan surat persetujuan berlayar. Sehingga kantor Kesyahbandaran Utama Makassar Bidang Keselamatan Berlayar terbantu dalam meningkatkan kinerja dan keselamatan kapal di pelabuhan. Aplikasi Desktop ini pula dapat menjadi media interaksi dan informasi antara pegawai kantor dengan pihak agen atau pemilik kapal, serta antara atasan kantor dengan pihak pelabuhan. Selain itu, dengan adanya aplikasi desktop ini dapat membantu mewujudkan program kantor yang berbasis teknologi.
\end{abstract}

Kata Kunci : Kantor Kesyahbandaran, Surat Izin Berlayar, Desk 


\section{Pendahuluan}

Kantor Kesyahbandaran Kelas Utama Makassar merupakan unit kerja organisasi kepelabuhanan yang bernaung di bawah Kementerian Perhubungan Republik Indonesia yang berkedudukan pada pelabuhan kelas Utama dan bertanggung jawab kepada Direktorat Jenderal Perhubungan Laut. Dimana Kantor Kesyahbandaran memiliki tugas dalam mengawasi kelaiklautan, keselamatan, keamanan, dan ketertiban di pelabuhan sesuai dengan UndangUndang No.17 tahun 2008 pasal 207 ayat 1 tentang tugas Syahbandar.

Lalu lintas kapal yang keluar dan masuk pelabuhan Soekarno Hatta Makassar sangat tinggi sehingga tingkat pelayanan yang diberikan juga harus lebih tepat, cepat, efektif dan efesien. Oleh karena itu peran Syahbandar perlu ditingkatkan melalui keterampilan nautis, teknis dan administratif serta disiplin kerja, peningkatan dedikasi terhadap pengembangan tugas demi mewujudkan keselamatan kapal, barang dan jiwa di laut.

Survei membuktikan bahwa dunia pelayaran menghadapi dilema dimana kecelakaan kapal masih saja terjadi dalam jumlah yang memprihatinkan, walaupun teknologi perkapalan dan komunikasi pelayaran sudah maju dan dapat dikatakan telah canggih. Untuk itu perlu di kaji dari berbagai faktor kecelakaan dan mencari langkahlangkah untuk mengurangi atau mengeliminasinya.

Dalam upaya meningkatkan kinerja dalam mengawasi kelaiklautan, keselamatan, keamanan dan ketertiban, di pelabuhan kantor Kesyahbandaran memiliki struktur organisasi dimana terdapat satu kepala bagian dan tiga kepala bidang, masing-masing bidang kelaiklautan kapal, bidang keselamatan berlayar, dan bidang ketertiban dan patroli. Didalam bidang keselamatan berlayar bertugas melaksanakan pengawasan tertib lalu lintas kapal di perairan pelabuhan dan alur pelayaran, pemanduan dan penundaan kapal, serta penerbitan Surat Persetujuan Berlayar.

Jumlah kapal masuk dan keluar dari pelabuhan tentu saja membutuhkan pengawasan yang baik dan administrasi order, untuk mencegah penumpukan kapal. Administrasi yang dimaksud adalah pemerintahan dalam arti sempit, yaitu: korespondensi yang berkaitan dengan pelaporan kegiatan kapten / perusahaan pelayaran mulai dari kedatangan kapal sampai kapal akan berangkat (berlayar) ke pelabuhan tujuan.

Disisi lain perkembangan teknologi berkembang begitu pesat. Kecanggihan teknologi yang paling dirasakan yaitu salah satunya dengan adanya teknologi komputer. Saat ini pemanfaatan komputer merupakan bagian yang tidak terpisahkan dengan kehidupan manusia, karena hampir semua aspek kehidupan manusia bersinggungan dengan teknologi komputer. Dalam perannya untuk membantu user (pengguna) mencapai suatu tujuan, komputer dapat menjalankan berbagai macam aplikasi dengan tujuan yang berbeda-beda salah satunya dengan menggunakan aplikasi desktop. Dengan aplikasi desktop pengguna mampu mendapatkan layanan, fasilitas dan informasi yang ditampilkan melalui links, navigasi, konten informasi yang dapat digunakan dengan mudah. Sehingga dapat menyelesaikan tugas melalui sebuah aplikasi dengan mudah, efektif dan efisien.

Berdasarkan latar belakang tersebut, peneliti ingin merancang suatu sistem pemeriksaan kapal berbasis desktop yang mampu membantu pegawai Kantor Kesyahbandaran Utama Makassar dalam mengatasi faktor kecelakaan dan mencari langkah-langkah untuk mengurangi atau mengeliminasinya. Sistem ini dirancang demi meningkatkan keselamatan berlayar dalam tingkat pemeriksaan kapal yang sesuai dengan bentuk dan alur berjalannya dalam penerbitan Surat Penertiban Berlayar (SOB). Selain itu sistem ini juga dibentuk dengan sistem aplikasi desktop yang dimana tingkat ketelitian dalam penginputan berkas-berkas yang ada akan lebih cermat, pegawai akan menginput berkas sesuai yang ada dalam sistem sehingga dapat meningkatkan kinerja dan mempercepat pengaksesan terkait masalah-masalah penerbitan dan kelengkapan surat berlayar kapal yang diharapkan dapat diatasi dengan baik dan maksimal.

\section{Metodologi Penelitian}

Penelitian kualitatif lapangan yang digunakan adalah Design and Creation. Penelitian Design and Creation merupakan studi sistematis desain, pengembangan dan evaluasi proses dengan tujuan membangun secara empiris untuk penciptaan produk instruksional dan non-instruksional dan alatalat dan model baru atau ditingkatkan yang 
mengatur perkembangan mereka (Richey dan Klein, 2009). Dipilihnya jenis penelitian ini oleh penulis dikarenakan konsep dari Design and Creation sangat tepat untuk mengelola penelitian ini. Di samping melakukan penelitian tentang judul ini, penulis juga mengembangkan produk berdasarkan penelitian yang dilakukan.

Adapun lokasi penelitian ini dilakukan di Kantor Kesyahbandaran Utama Makassar Bidang Keselamatan Berlayar Pelabuhan Soekarno Hatta Makassar dan Laboratorium Pemrograman Sistem Informasi.

Analisis sistem dilakukan melalui empat tahapan yaitu :

a. Survei atas sistem yang sedang berjalan Pada tahap ini, penulis melakukan pengumpulan data yang dibutuhkan yaitu dengan cara mengadakan survei melalui wawancara, pengamatan langsung dan pengadaan kuisioner terhadap sistem yang sedang berjalan.

b. Analisis terhadap temuan survei Pada tahap ini, penulis melakukan analisa terhadap temuan survei untuk mengidentifikasi masalah yang ada, sehingga pada akhirnya penulis dapat menentukan sasaran-sasaran yang akan dicapai dari penulisan skripsi ini.

c. Identifikasi kebutuhan informasi pada tahap ini, penulis menemukan masalah dan melakukan identifikasi kebutuhan informasi yang dibutuhkan oleh studi kasus sehingga dapat mencapai tujuan dari solusi yang diberikan.

d. Identifikasi persyaratan sistem pada tahap ini, penulis melakukan identifikasi atas apa saja yang perlu dikembangkan untuk memenuhi kebutuhan yang ada sebelum melakukan perancangan sistem yang baru.

Penelitian ini menggunakan pendekatan penelitian saintifik dan tindakan yaitu pendekatan berdasarkan ilmu pengetahuan dan teknologi serta bertujuan untuk mengembangkan keterampilan baru atau pendekatan baru dan diterapkan langsung serta dikaji hasilnya. Sumber data pada penelitian ini adalah menggunakan sumber data kualitatif data primer. Data primer adalah berbagai informasi dan keterangan yang diperoleh langsung dari sumbernya, yaitu para pihak yang dijadikan informan penelitian. Dimana penelitian bertujuan merancang sebuah aplikasi guna memudahkan pegawai instansi dalam pengolahan sistem yang berjalan Kebutuhan-kebutuhan data untuk perancangan aplikasi dekstop ini sebagai berikut :

a. Data bendera kapal, data agen pemilik kapal, dan data kapal.

b. Data dokumen yang nantinya akan menjadi proses pemeriksaan dokumen kapal.

c. Proses pemeriksaan dokumen kapal dan bentuk surat izin berlayar atau surat persetujuan berlayar.

\section{HaSil dan Pembahasan}

Halaman ini merupakan halaman yang menampilkan menu utama yang berupa daftar bendera, daftar agen, daftar kapal, daftar jenis dokumen, daftar dokumen kapal, pemeriksaan dokumen, surat izin dan menu log out. Adapun gambar jelas tampilan halaman utama dapat dilihat pada Gambar V.2

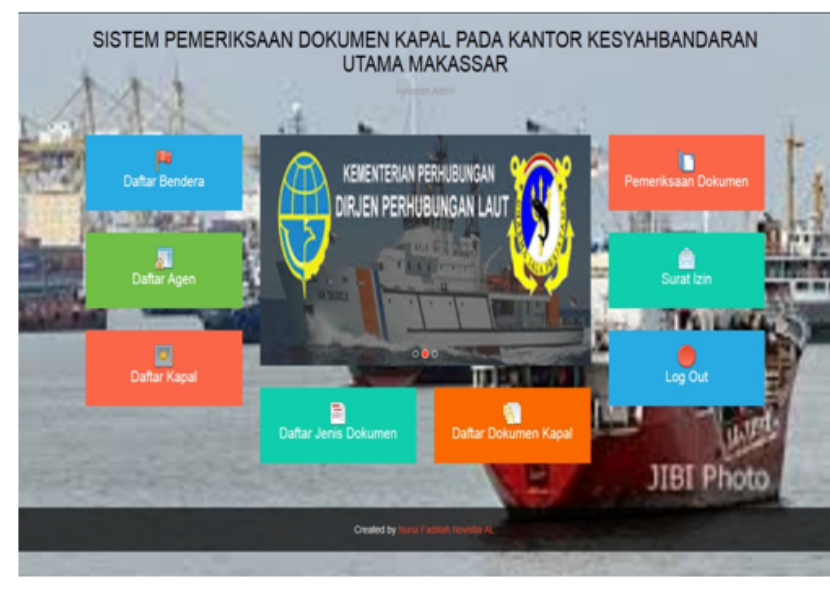

Gambar V. 2. Halaman Utama

Halaman ini menampilkan kode, nama, gambar bendera serta terdapat action untuk mengedit atau menghapus. Pengolahan data yang dimaksud disini ialah admin dapat menambah data bendera. Selain itu, admin juga dapat menghapus bendera yang sudah terdaftar. Adapun gambar jelas daftar bendera dan data user tambah pada halaman daftar bendera dapat dilihat pada Gambar V.3 dan V.4 : 


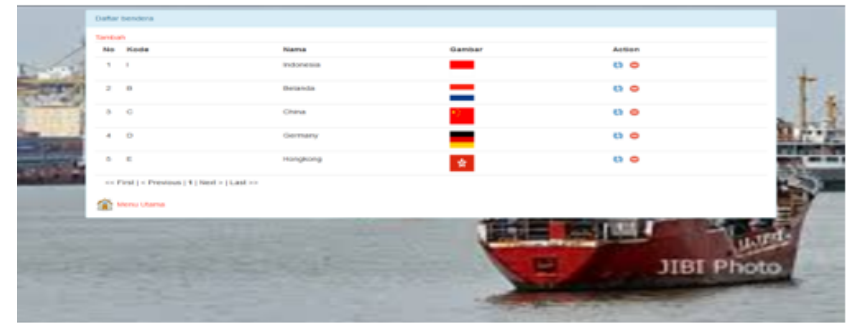

Gambar V. 3. Halaman Daftar Bendera

Halaman ini menampilkan kode, nama, alamat, no.telpon serta foto agen dan terdapat menu action untuk mengedit atau menghapus. Halaman ini juga digunakan untuk mengolah data user yang dapat menambah data agen. Berikut ini tampilan dari halaman daftar agen dan data user tambah pada halaman daftar agen pada Gambar V.5 dan V.6:

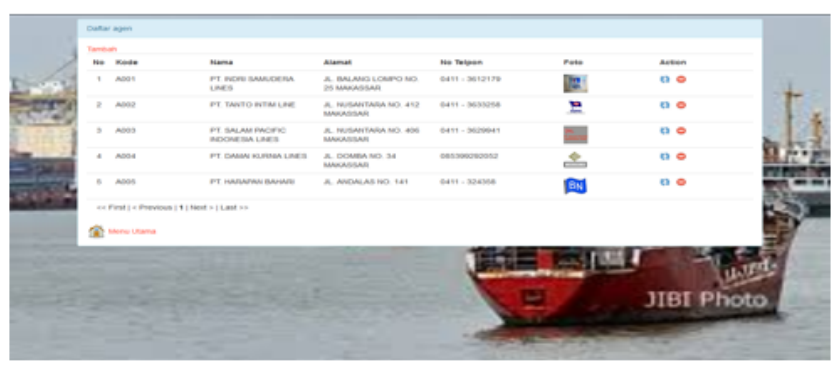

Gambar V. 5. Halaman Daftar Agen

Pada gambar V.5 menampilkan semua data agen pemilik kapal yang berlabuh di pelabuhan.
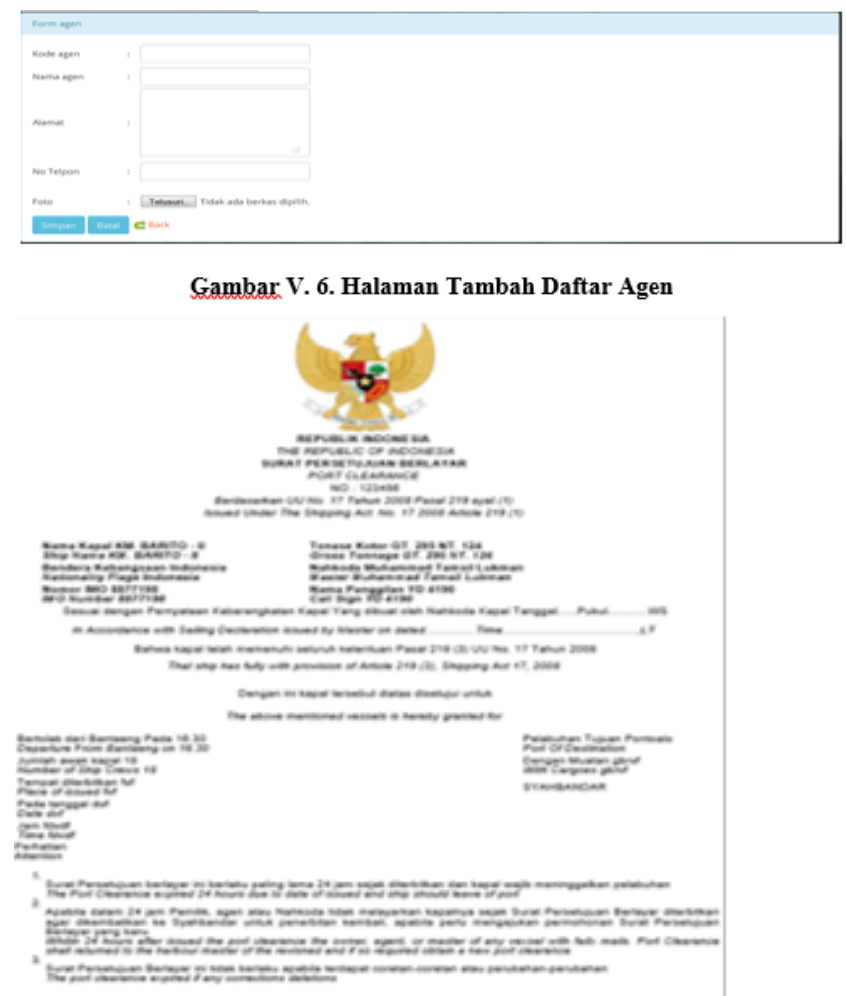

\section{Gambar V. 16. Tampilan Surat Izin Berlayar-}

Pada gambar V.16 merupakan hasil output dari tombol pencetakan surat izin berlayar
Hasil Kuesioner Jumlah Responden : 20 mengenai pengujian sistem

\begin{tabular}{|c|l|c|c|c|c|c|}
\hline \multirow{2}{*}{ No } & \multicolumn{2}{|c|}{ KRITERIA } & \multicolumn{5}{|c|}{ PENILAIAN } \\
\cline { 3 - 8 } & & 5 & 4 & 3 & 2 & 1 \\
\hline 1. & $\begin{array}{l}\text { Bagaimana penilaian tentang tampilan } \\
\text { aplikasi dekstop? }\end{array}$ & $\mathbf{5 0 \%}$ & $\mathbf{4 5} \%$ & $\mathbf{5} \%$ & - & - \\
\hline
\end{tabular}

\begin{tabular}{|c|c|c|c|c|c|c|}
\hline 2. & $\begin{array}{l}\text { Penilaian tentang kemudahan untuk } \\
\text { mengakses aplikasi dekstop? }\end{array}$ & $70 \%$ & $30 \%$ & - & - & - \\
\hline 3. & $\begin{array}{l}\text { Bagaimana komposisi warna pada } \\
\text { aplikasi dekstop? }\end{array}$ & $10 \%$ & $40 \%$ & $50 \%$ & - & - \\
\hline 4. & Struktur menu yang disajikan? & $65 \%$ & $35 \%$ & - & - & - \\
\hline 5. & $\begin{array}{l}\text { Konsistensi tampilan layar pada dekstop } \\
\text { ? }\end{array}$ & $70 \%$ & $20 \%$ & $10 \%$ & - & - \\
\hline 6. & Kelengkapan konten data yang diolah? & $85 \%$ & $15 \%$ & - & - & - \\
\hline 7. & Kelengkapan informasi yang disajikan? & $65 \%$ & $20 \%$ & $15 \%$ & - & - \\
\hline 8. & $\begin{array}{l}\text { Bagaimana penilaian anda tentang fitur } \\
\text { dokumen kapal yang ada? }\end{array}$ & $75 \%$ & $70 \%$ & $5 \%$ & - & - \\
\hline 9. & $\begin{array}{l}\text { Bagaimana penilaian anda tentang fitur } \\
\text { pemeriksaan kapal ? }\end{array}$ & $85 \%$ & $15 \%$ & - & - & - \\
\hline 10. & $\begin{array}{l}\text { Bagaimana penilaian anda tentang fitur } \\
\text { penerbitan surat izin berlayar? }\end{array}$ & $85 \%$ & $10 \%$ & $5 \%$ & - & - \\
\hline
\end{tabular}

11. Apakah aplikasi ini bermanfaat dalam dalam proses pemeriksaan dokumen kapal?

- Dari hasil penelitian 100\% responden mengatakan sangat bermanfaat.

12. Apakah aplikasi ini lebih efisien dibandingkan jika menggunakan pengolahan data pemeriksaan dokumen secara manual?

-Dari hasil penelitian 100\% responden mengatakan sangat efisien.

13. Perlukah aplikasi ini dipergunakan dalam pengolahan penerbitan surat izin berlayar?

-Dari hasil penelitian $100 \%$ responden mengatakan sangat sangat perlu

14. Apa kekurangan dari aplikasi sistem pemeriksaan kapal berbasis dekstop ini?

-Dari hasil penelitian 70\% mengatakan belum memiliki fitur perpanjangan dokumen kapal yang expired.

$20 \%$ mengatakan tidak ada layanan online akses pada agen.

\section{KESIMPULAN}

Dari hasil pengujian dan pembahasan yang dibuat, maka telah dihasilkan suatu sistem pemeriksaan kapal yang dapat disimpulkan bahwa sistem pemeriksaan kapal berbasis desktop ini memberikan kemudahan dalam pengolahan data kapal yang masuk dan keluar sehingga pegawai 
kantor kesyahbandaran utama bidang keselamatan berlayar dapat dengan mudah menginput dokumen yang telah dipenuhi kapal. Serta, sistem pemeriksaan kapal ini lebih mengefesiensikan waktu pegawai dalam pengolahan berkas dokumen kapal dalam penerbitan surat persetujuan berlayar sesuai dengan prosedur dokumen yang ada.

\section{DAFTAR PUStaka}

Departemen Agama. Al Quran Surah Al-Baqarah Ayat 164. Al Quran dan Terjemahannya. Departemen Agama RI. 2007.

Departemen Perhubungan."Kantor Kesyahbandaran dan Otoritas Pelabuhan". Official Website Department Perhubungan. m.dephub.go.id/Kantor Kesyahbandaran dan Otoritas Pelabuhan ( 15 Juni 2004)

Dwi Prasetyo, Didik. Administrasi Database Server MySQL. Bandung : Elex Media Computindo. 2002.

Hopwood "Pengertian Sistem dan Informasi". Edisi I.Yogyakarta: Andi Offset.2001.

Jogianto,

2005.

http://www.sarjanaku.com/2012/11/pengertiansistem-menurut-para-ahli.html (Diakses 07 21, 2015).

Kadir.

https://agusdar.wordpress.com/2013/04/13/meto de-pengembangan-sistem-waterfall/ (Diakses Juli 21, 2015).

Kreibich, Jay A. Using SQLite. United State of America: O'Reilly Media, 2010.

Moelong. 2002. _METODE.pdf-Foxit PhantomPDF Express (Diakses Juli 21, 2015).

Peraturan Menteri Perhubungan Nomor : KM 64 Tahun 2010 dan PM 34 Tahun 2012

Peraturan Menteri Negara Pendayagunaan Aparatur Negara dan Reformasi Birokrasi dalam surat nomor B/2237/M.PAN-RB/10/2010 tanggal 7 Oktober 2010

Perhubungan, Kementrian. Prosedur Pelayanan Kapal Tiba dan Pelayanan Kapal Tolak. 2008.

Safaat, Harahap Nazaruddin. Pemrograman Aplikasi Mobile Smartphone dan Tablet PC. Bandung: Informatika, 2011.
Sunarko, Braska Jaya. "Aplikasi Permohonan Pemeriksaan Hewan di Balai Besar Karantina Pertanian Surabaya." 2012.

Saputro. "Perancangan Sistem Aplikasi Daftar Tunggu Pasien Berbasis Desktop di UPT Puskesmas Wonosari II”.2010.

Schell. "Defenisi Sistem dan Pengertiannya". Yogyakarta : Penerbit Gaya Media. 2004.

Wikipedia. 2015. https://tyomulyawan.wordpress.com/sistemdan-informasi/ (Diakses Juli 21, 2015).

Yuliani, Muhammad Arief Andry dan Febri. "Implementasi Kebijakan Keselamatan Pelayaran." 2014.

Jogiyanto. Pengenalan Komputer. Yogyakarta: Andi. 2005.

Kadir, Abdul. Dasar Perancangan dan Implementasi Database Relasional, Edisi I. Yogyakarta: Andi Offset. 2009

Kadir, Abdul. Dasar Pemrograman Web Dinamis Menggunakan PHP. Yogyakarta: Andi Offset. 2003.

Kartodirdjo,

Sartono.

2012. http://www.lepank.com/2012/07/pengertianseni-budaya-menurut-beberapa.html (diakses 25 Juni 2015).

Krismiaji. Sistem Informasi Akuntansi. Jakarta.2010.

Sulastianto, Harry. http://fatih-io.biz/pengertian-senimenurut-para-ahli.html (diakses 4 Juli 2015).

Supardi, Yanuar. Analisis dan Desain Sistem Informasi. Jakarta : PT. Gramedia Pustaka Utama. 2010.

Supriyanto, Aji. Pengantar Teknologi Informasi. Jakarta: Salemba Infotek. 2005.

Sutarman, Membangun Aplikasi web dengan PHP dan MySQL. Yogyakarta : Graha ilmu. 2003.

Taylor, E.B. Primitive Culture. New York : Brentano's, 1924.

uin-alauddin.ac.id. http://uin-alauddin.ac.id/sejarah (diakses 4 Juli 2015).

Pressman, Roger S. Software Engineering. Yogyakarta: Sumber Ilmu. 2001.

Wahana Komputer, Seri Panduan Lengkap Menguasai Pemrograman Web Dengan PHP 5. Yogyakarta : Penerbit Andi. 2006 